\title{
Quantitative Trading Strategy of Market States Prediction Based on HMM
}

\author{
Fu Zhongjie ${ }^{1, a}$, Wu Qingqiang ${ }^{1, b, *}$ \\ ${ }^{1}$ Software School, Xiamen University, Xiamen, Fujian, China \\ a fuzhongjie@stu.xmu.edu.cn, ${ }^{\mathrm{b}}$ wuqq@xmu.edu.cn \\ *corresponding author
}

Keywords: Hidden Markov models, Market states prediction, Trading strategy.

\begin{abstract}
Hidden Markov model has been widely applied in various fields and has obtained excellent effects. In this paper, we verify the feasibility of applying HMM to quantitative finance and the potential to obtain stable profits and detect coming bear market to avoid sharp falling process. We creatively make full use of raw data and list a few candidate features. Corresponding feature selection method, which uses HMM itself to test performance on each single feature, has been proposed. The comprehensive model is trained using selected features and is tested performance on CSI 300 index in Chinese Astock market and S\&P 500 index in American stock market. Experiments on both markets illustrate that HMM has great ability to identify market states and obtain excess return. And HMM-based strategy has better stability and profitability compared with strategies based on double-MA and K-means. HMM is appropriate to be applied as the core of quantitative strategies to judge the trends of financial markets.
\end{abstract}

\section{Introduction}

Although financial market is rather difficult to be predicted precisely, it's possible to predict the trends or the states of the market in the next period of time. Several literatures have indicated that there are different states in financial markets, especially in stock and bond markets. Guidolin and Timmermann [1] verified that there are crash, slow growth, bull and recovery states in stock and bond markets. De Angelis and Paas [2] proposed a framework to detect stable and turmoil periods and predict the switch between two states. Salhi, Deaconu [3] used HMM to classify data in crisis and steady periods. Furthermore, various methods have been researched and used to predict markets trends in the future. Cao and Tay [4] used support vector machines to forecast future trends on S\&P 500 daily price time series. Galeshchuk [5] found the neural network with the best forecasting abilities and used it for time-series predictions on exchange market data. Bebarta, Sudha [6] applied ensemble learning and combined artificial neural networks, hidden Markov models and genetic algorithms to construct a framework of a stock forecasting system. In consequence of the difficulty of giving suitable label manually for stock price, unsupervised methods like hidden Markov model have been researched a lot. Hassan and Nath [7] made use of HMM to find the most similar day in the past with today to forecast tomorrow's stock price. They offered a new paradigm for stock market forecasting. After that, Park, Lee [8] used continuous HMM to forecast change direction of next day's closing price, and Seethalakshmi, Krishnakumari [9] took advantage of HMM to classify data in crisis and steady periods. Other traditional statistical methods like auto-regressive and 
moving average model or auto-regressive integrated moving average model, which seem to be more suitable for stationary time series, have also been applied.

Hidden Markov model plays an important role in natural language processing [10] and speech recognition [11]. The concept of state transition is appropriate for fields with certain number of states. Therefore, the main objective of HMM is to capture the rule behind observations and to forecast possible states in the future.

In this paper, we return to nature and make use of the characteristics of HMM to recognize and forecast market state. We regard observable features as observations, and the market states as hidden states. First, some candidate features are extracted from historical data of stock market indices. Later, several effective features are selected from these features according to evaluation indicators. Then, an HMM model, which has been given certain state number, is trained using these selected features. Finally, the model is used to forecast the next day's market state given features of previous days.

In this paper, we present HMM-based market states forecasting method to generate index fund trading strategy. The strategy's effectiveness is evaluated from various aspects and compared with two other methods. We also discuss the drawbacks and limitations of this method.

The rest of the paper is organized as follows. In section 2, the basic theory of HMM is introduced and the trading strategy is described comprehensively. In section 3 we show some experimental results on data from Chinese A-share market, and we also test this method on international market like Standard \& Poor's 500 (S\&P 500) Index. Comparison results between HMM and double-MA and k-means are also shown in this section. In section 4, the paper is concluded.

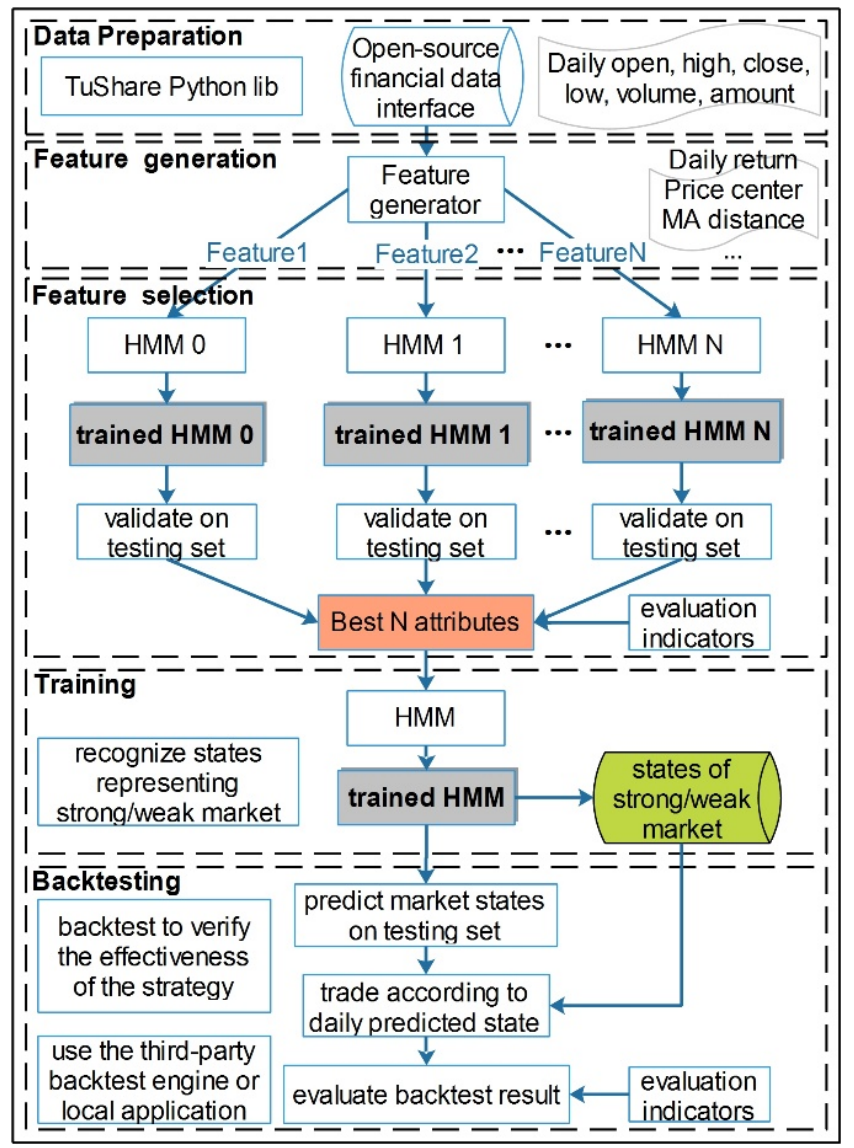

Figure 1 Flow diagram of the model. 


\section{Methodology}

The overall process of the model is described in Figure 1. Open source data interface is called to obtain original daily trading data with a few candidate relative features calculated. To figure out which features have outstanding ability of making profits, single HMM model is applied to each feature to test the performance using AHP so that we could pick out effective features. After that, given the number of states, the final HMM forecasting model is trained using selected features and the candidate states which may bring profits are recognized. For backtesting step, the main goal is to test the generalization ability of this strategy. After all the above steps, the best parameters of the model have been obtained and could be applied to forecast the next trading day's market state in practice.

\subsection{Features preparation}

According to previous researchers, most of them only use intraday Open, Close, High and Low prices as features to train the model. In this paper, we replace aforementioned raw features with those extracted from original data based on related calculations.

Actually, there are quite a few possible candidate features, which can be classified into technical and fundamental ones. Technical features refer to common technical indicators such as relative strength index, money flow index and average true range. And fundamental features contain indicators revealing the state of national economy including liquidity and commodity prices like CPI and M1. All the above features describe current economic situation and status of financial markets from different aspects. In consideration of the difficulty of obtaining macroeconomic data from other countries and the demands of universality of our model, we mainly research on technical features in our model in the subsequent research.

\subsection{Features selection}

The primary task of this part is to pick out high-quality features from all the candidate features. Different features reflect market states in different degrees and from different perspectives, and gathering these features together forms a complementary relationship, which improves the model. Nevertheless, there are some invalid factors, which have weak impact on recognizing current market state.

We use a naïve idea to finish this job. According to Figure 1, after generating various kinds of candidate features, we build HMM model for each of these features and execute single-feature testing. Via backtesting model and observing performance through evaluation indicators, we could compare these features and judge their effectiveness. There are lots of indicators that can be used to evaluate the performance, such as annualized return, drawdown and Sharpe ratio. With multiple evaluation indicators, the analytical hierarchy approach is taken. Different weights are given for different indicators subsequently. Finally, we get the comprehensive score for each feature and manage to pick out the best $\mathrm{k}$ features and form them into group of features for the final HMM model.

\subsection{Training}

\subsubsection{Reasonability}

HMM is a Markov model in which the system being modelled is assumed to be a Markov process with hidden states. Different with simple Markov model, states are not directly visible in 
HMM. Each state has a probability distribution over the possible outputs. Hence, the sequence of observations reflects the changes of hidden states. As a result, HMM are known for its application in temporal pattern recognition such as speech, handwriting [12] and gesture recognition [13]. In the standard type of hidden Markov model, the state space of the hidden variables is discrete, while the observations themselves can either be discrete or continuous. In this paper, we assume that all the features follow the Gaussian distribution.

The first-order Markov model assumes that the current state only depends on the previous state. Under this assumption, information from $T-n$ ( $T$ represents today, $n \geqslant 2$ ) days is lost, which does not conform to the reality. However, this assumption simplifies the process, reduces the complexity of the model and makes it easier to be understood and explained. HMM holds an assumption that each observation only depends on the current hidden state, which is in line with our interpretation of market. There are significant differences between bull and bear markets on return rate and volatility, so we have reasons to believe that observations have variant distributions under different market states. Also, the distribution only depends on the market states. And HMM only has one main parameter - the number of states, which avoids the model from overfitting, improves the stability of the model and saves time from adjusting parameters. Unlike other models like artificial neural network, the result of HMM can be interpreted easily. Although the hidden states in HMM are abstract, we can give posterior explanation for each state. All the hidden states can be distinguished as profitable or unprofitable states according to their cumulative return on training set.

In summary, HMM model has its advantages of simplicity, robustness and interpretability. Yet the major weaknesses are the partial loss of historical information and the lack of direct explanation for each state.

\subsubsection{States selection}

To distinguish profitable and unprofitable states, we execute long strategy and obtain a cumulative return curve for each state. We can just simulate the process of feature selection and concern various evaluation indicators. One possible method is to weight for above indicators and get comprehensive assessment for each state. For simplicity, we classify all the states into 2 types according to their cumulative return, and label 1 for profitable states, and 0 for unprofitable ones. Then the long or short strategies will be executed on these states according to their type respectively. Equation (1) gives an example on how to distinguish profitable states.

$$
\begin{aligned}
& \text { choose this state, if: } \\
& \qquad \begin{array}{l}
\text { cumulative_return } \\
\quad>5 \% \& \text { there's no i, in which cumulative_return } \\
\quad<-3 \%)
\end{array}
\end{aligned}
$$

There still exists a key issue. Some states will lose effectiveness for some period, and some will rather become profitable. In other words, valid states are always dynamic, especially when the proportion of selected states is high, which will introduce "unfaithful" state. To solve this problem, we apply an intuitive idea to adapt to this requirement - dynamic states pool. We check above condition for each state every day. Once some state satisfies the condition, it will be added into the target states pool and long strategy will be executed for this state from that day. Conversely, if the state fails to meet the condition, it will be removed from the pool. 


\subsection{Backtest}

\subsubsection{Trading strategy}

The main goal of this paper is to verify the feasibility of applying HMM to market timing and its ability to avoid the crash. Therefore, we prefer representative object of transaction with high stability. Although Chinese stock market has developed for about 30 years, recent research like [14] have proved that the Chinese A-share stock market is still an inefficient market. In order to avoid high volatility of individual stock, it's better to choose market indices as our target.

As the trained HMM can tell exact market state for the next day, we can trade on corresponding ETF according to the predicted state. If the predicted state represents strong market and we have no position at present, then we will open long position at the opening on the next trading day. On the contrary, if the predicted state represents weak market, we will close position if we keep long position or just keep still when there is no position. Without any position control measurements, we use all our available capital for trading. Namely, the position ratio is close to 1.

\subsubsection{Evaluations}

Superior investment performance is the product of careful attention to four elements also called the performance pyramid. Return refers to the ability to obtain absolute and excess returns, which is the basic requirement for a strategy. People often use annualized returns and excess returns to measure the ability. It refers to the speed to make profits, and implies the ability to beat the market. Furthermore, risk is also an important factor to be considered. As stability of a strategy helps to avoid great losses in terrible market circumstances, a strategy with low risk can provide a low drawdown. Trading cost must also be considered as excessive trading results in inefficient trading in most cases. For instance, in China, security companies collect about 1.5\%o commission in each transaction. In the long run, it will be a huge expense and erode profits. Thus, it's important to keep relatively high winning rate of trading and appropriate trading frequency. The use of daily data determines that the strategy is a day-level strategy. We monitor daily states and make corresponding trading decisions on the next day. We haven't thought about any position control, stop-loss or takeprofit measurements. All these risk management measurements will certainly further control the risk at a lower level.

\section{Experiments}

\subsection{Data}

To simplify the experiments, we prefer stock market indices as our experimental subjects. For single stock, there are mainly two disadvantages. First, single stock has much higher volatility compared with market indices. Second, single stock exists the mechanism of sharing out bonus, which leads to sudden change of price information. As a result, we select CSI 300 index as our tracking trading target for Chinese market and S\&P 500 index for international market. The CSI 300 is a capitalization-weighted stock market index designed to replicate the performance of 300 stocks traded in the Shanghai and Shenzhen stock exchanges. The S\&P 500 is a leading index which consists of 500 stocks selected by economists. ETF is the exchange traded fund with the same constituent stocks with corresponding tracked target, such as CSI 300 index (300ETF) and AU99.99 (Au ETF). Logically, we choose 300ETF as our trading target to simulate real trading scenario. And the original data structure is shown as Table 1. 
Table 1 Data structure and samples of raw data from TuShare.

\begin{tabular}{|c|c|c|c|c|c|c|}
\hline Date & Open & High & Close & Low & Volume & Amount \\
\hline $2015-03-16$ & 13.27 & 13.45 & 13.39 & 13.00 & 81212976 & 1073862784 \\
\hline $2015-03-13$ & 13.04 & 13.38 & 13.37 & 13.00 & 40548836 & 532739744 \\
\hline $2015-03-12$ & 13.29 & 13.29 & 13.28 & 12.96 & 71505720 & 962979904 \\
\hline
\end{tabular}

\subsection{Features selection}

As mentioned in part 2.2, we select features according to certain evaluation indicators. In our experiments, we assign these indicators different weights respectively. Finally, we pick out 6 features: close return, price efficiency (20 days), MACD, ATR (14 days), BR and MFI. Table 2 describes the performance of these features from 2014 to 2016. The results in this table is the statistical average of state numbers from 2 to 13. Some features perform significantly according to specific state numbers. The data in parentheses represents the results of state number with highest cumulative return.

Table 2 The average testing results of selected features.

\begin{tabular}{|c|c|c|c|c|c|c|c|}
\hline \multicolumn{2}{|c|}{ Features } & $\begin{array}{c}\text { Close return } \\
6^{*}\end{array}$ & $\begin{array}{l}\text { Price efficiency(20) } \\
4 *\end{array}$ & $\begin{array}{l}\text { MACD } \\
5^{*}\end{array}$ & $\begin{array}{l}\operatorname{ATR}(14) \\
3^{*}\end{array}$ & $\begin{array}{l}\mathrm{BR} \\
9 *\end{array}$ & $\begin{array}{c}\text { MFI } \\
4^{*}\end{array}$ \\
\hline \multicolumn{2}{|c|}{ Winning rate } & $\begin{array}{c}51.05 \% \\
(53.33 \%)\end{array}$ & $\begin{array}{c}55.03 \% \\
(59.65 \%)\end{array}$ & $\begin{array}{c}51.74 \% \\
(55.56 \%)\end{array}$ & $\begin{array}{c}71.63 \% \\
(50.00 \%)\end{array}$ & $\begin{array}{c}51.58 \% \\
(48.48 \%)\end{array}$ & $\begin{array}{c}44.54 \% \\
(56.52 \%)\end{array}$ \\
\hline \multirow{2}{*}{ Frequency } & Open & $\begin{array}{l}18.2 \\
(16)\end{array}$ & $\begin{array}{l}68.5 \\
(58)\end{array}$ & $\begin{array}{l}28.7 \\
(18)\end{array}$ & $\begin{array}{l}4.3 \\
(5)\end{array}$ & $\begin{array}{l}31.0 \\
(33)\end{array}$ & $\begin{array}{l}32.3 \\
(23)\end{array}$ \\
\hline & Close & $\begin{array}{l}17.5 \\
(15)\end{array}$ & $\begin{array}{l}67.5 \\
(57)\end{array}$ & $\begin{array}{l}28.7 \\
(18)\end{array}$ & $\begin{array}{l}3.4 \\
(4)\end{array}$ & $\begin{array}{l}31.0 \\
(33)\end{array}$ & $\begin{array}{l}32.3 \\
(23)\end{array}$ \\
\hline \multicolumn{2}{|c|}{ Cumulative return } & $\begin{array}{c}47.97 \% \\
(\mathbf{9 7 . 2 0 \% )}\end{array}$ & $\begin{array}{c}59.79 \% \\
(92.34 \%)\end{array}$ & $\begin{array}{c}35.19 \% \\
(67.83 \%)\end{array}$ & $\begin{array}{c}47.03 \% \\
(73.45 \%)\end{array}$ & $\begin{array}{c}37.01 \% \\
(49.10 \%)\end{array}$ & $\begin{array}{c}18.96 \% \\
(42.96 \%)\end{array}$ \\
\hline \multicolumn{2}{|c|}{ Annualized Return } & $\begin{array}{l}15.34 \% \\
(31.07 \%)\end{array}$ & $\begin{array}{l}19.12 \% \\
(29.52 \%)\end{array}$ & $\begin{array}{l}11.25 \% \\
(21.68 \%)\end{array}$ & $\begin{array}{l}15.04 \% \\
(23.48 \%)\end{array}$ & $\begin{array}{l}11.90 \% \\
(15.70 \%)\end{array}$ & $\begin{array}{c}6.09 \% \\
(13.73 \%)\end{array}$ \\
\hline \multicolumn{2}{|c|}{ Maximum drawdown } & $\begin{array}{l}26.86 \% \\
(19.53 \%) \\
\end{array}$ & $\begin{array}{c}22.95 \% \\
(24.05 \%)\end{array}$ & $\begin{array}{c}16.95 \% \\
(21.92 \%)\end{array}$ & $\begin{array}{c}12.76 \% \\
(15.26 \%)\end{array}$ & $\begin{array}{l}22.68 \% \\
(23.14 \%)\end{array}$ & $\begin{array}{l}21.39 \% \\
(22.29 \%)\end{array}$ \\
\hline \multicolumn{2}{|c|}{ Sharpe ratio } & $\begin{array}{l}1.10 \\
(1.38)\end{array}$ & $\begin{array}{c}1.34 \\
(1.32)\end{array}$ & $\begin{array}{c}0.83 \\
(1.41)\end{array}$ & $\begin{array}{l}1.40 \\
(1.38)\end{array}$ & $\begin{array}{c}1.24 \\
(1.29)\end{array}$ & $\begin{array}{c}0.95 \\
(1.24)\end{array}$ \\
\hline \multicolumn{2}{|c|}{ Cost } & $\begin{array}{c}7072 \\
(7139)\end{array}$ & $\begin{array}{l}26163 \\
(25651)\end{array}$ & $\begin{array}{c}8679 \\
(6539)\end{array}$ & $\begin{array}{c}1396 \\
(1853)\end{array}$ & $\begin{array}{c}10529 \\
(11789)\end{array}$ & $\begin{array}{c}9814 \\
(7904)\end{array}$ \\
\hline \multicolumn{2}{|c|}{$\frac{\text { return }}{\text { drawdon }}$} & $\begin{array}{c}2.31 \\
(4.98)\end{array}$ & $\begin{array}{c}2.81 \\
(3.84)\end{array}$ & $\begin{array}{c}2.34 \\
(3.09)\end{array}$ & $\begin{array}{c}3.82 \\
(4.81)\end{array}$ & $\begin{array}{c}1.64 \\
(2.12)\end{array}$ & $\begin{array}{c}0.86 \\
(1.93)\end{array}$ \\
\hline
\end{tabular}

*. for best state number

\subsection{States selection}

Table 3 Part of results on CSI 300 index (2014-2016).

\begin{tabular}{|c|c|c|c|c|c|c|c|c|c|c|}
\hline \multirow{2}{*}{$\begin{array}{c}\text { States } \\
\text { number }\end{array}$} & \multirow{2}{*}{$\begin{array}{l}\text { Selected } \\
\text { number }\end{array}$} & \multirow{2}{*}{$\begin{array}{l}\text { Winning } \\
\text { rate }\end{array}$} & \multicolumn{2}{|c|}{ Frequency } & \multirow{2}{*}{ Return } & \multirow{2}{*}{$\begin{array}{c}\text { Annualized } \\
\text { yield }\end{array}$} & \multirow{2}{*}{$\begin{array}{l}\text { Maximum } \\
\text { drawdown }\end{array}$} & \multirow{2}{*}{$\begin{array}{l}\text { Sharpe } \\
\text { ratio }\end{array}$} & \multirow{2}{*}{ Cost } & \multirow{2}{*}{$\frac{\text { return }}{\text { drawdown }}$} \\
\hline & & & Open & Close & & & & & & \\
\hline \multirow{2}{*}{6} & 1 & $42.86 \%$ & 14 & 14 & $3.24 \%$ & $1.04 \%$ & $10.16 \%$ & 1.26 & 4032 & 0.32 \\
\hline & 4 & $80.00 \%$ & 6 & 5 & $99.92 \%$ & $31.94 \%$ & $16.28 \%$ & 1.36 & 2513 & 6.14 \\
\hline \multirow{2}{*}{7} & 3 & $61.54 \%$ & 14 & 13 & $35.26 \%$ & $11.27 \%$ & $24.35 \%$ & 1.29 & 4976 & 1.45 \\
\hline & 4 & $54.55 \%$ & 12 & 11 & $53.43 \%$ & $17.08 \%$ & $26.17 \%$ & 1.35 & 4972 & 2.04 \\
\hline \multirow{2}{*}{8} & 2 & $57.14 \%$ & 7 & 7 & $31.41 \%$ & $10.04 \%$ & $7.74 \%$ & 1.39 & 2411 & 4.06 \\
\hline & 3 & $36.36 \%$ & 11 & 11 & $47.25 \%$ & $15.10 \%$ & $14.27 \%$ & 1.41 & 4234 & 3.31 \\
\hline \multirow{2}{*}{9} & 3 & $55.56 \%$ & 10 & 9 & $65.53 \%$ & $20.95 \%$ & $12.27 \%$ & 1.42 & 3906 & 5.34 \\
\hline & 4 & $69.23 \%$ & 14 & 13 & $105.14 \%$ & $33.61 \%$ & $12.30 \%$ & 1.32 & 6063 & 8.55 \\
\hline
\end{tabular}


Table 4 results on CSI 300 index using 9-state HMM model with dynamic states selection.

\begin{tabular}{|c|c|c|c|c|c|c|c|c|c|c|}
\hline \multirow{2}{*}{$\begin{array}{c}\text { States } \\
\text { number }\end{array}$} & \multirow{2}{*}{$\begin{array}{c}\text { Selected } \\
\text { number }\end{array}$} & \multirow{2}{*}{$\begin{array}{l}\text { Winning } \\
\text { rate }\end{array}$} & \multicolumn{2}{|c|}{ Frequency } & \multirow{2}{*}{ Return } & \multirow{2}{*}{$\begin{array}{c}\text { Annualized } \\
\text { yield }\end{array}$} & \multirow{2}{*}{$\begin{array}{l}\text { Maximum } \\
\text { drawdown }\end{array}$} & \multirow{2}{*}{$\begin{array}{l}\text { Sharpe } \\
\text { ratio }\end{array}$} & \multirow{2}{*}{ Cost } & \multirow{2}{*}{$\frac{\text { return }}{\text { drawdown }}$} \\
\hline & & & Open & Close & & & & & & \\
\hline 9 & $3 \rightarrow 4$ & $66.67 \%$ & 13 & 12 & $101.87 \%$ & $32.57 \%$ & $12.29 \%$ & $1.32 \%$ & 5596 & 8.29 \\
\hline
\end{tabular}

Combining selected features in Table 2, we could train a composite HMM model. For different markets, there are different ideal state number. During the experiments, we find that some states could transform from "bad" states to "good" states, which means that the dynamic states selection is necessary. In fact, the latent meaning of states is uncertain. Perhaps the states mean money effect in a certain period, or maybe they just mean the volatility of the current market. In this circumstance, we may control the latent meaning by giving different feature sets, explaining why the feature "close return" has the highest cumulative return rate as shown in Table 2.

In order to explore the biggest profit space by using dynamic states selection, we bring in "future function" here. The training set is defined between 2005 and 2013, and the testing set between 2014 and 2016, then the condition defined by Equation (1) is observed on the whole range from 2005 to 2016. By doing so, another selected state set called "future state set" can be obtained. Table 3 shows the forecasting ability of mixed selected features and the maximum potential to get higher cumulative return, and the results using future state set are displayed in grey. In most cases, there will be at least one extra state which can provide revenue on testing set. The gain brought by the additional states is significant. Table 4 gives the results using 9-state HMM model with dynamic states selection, which is just close to the full potential return rate of $105.14 \%$ in Table 3 . Figure 2 shows the market movements during the three years on testing set. And the benchmark yield of CSI 300 is about $43.95 \%$.

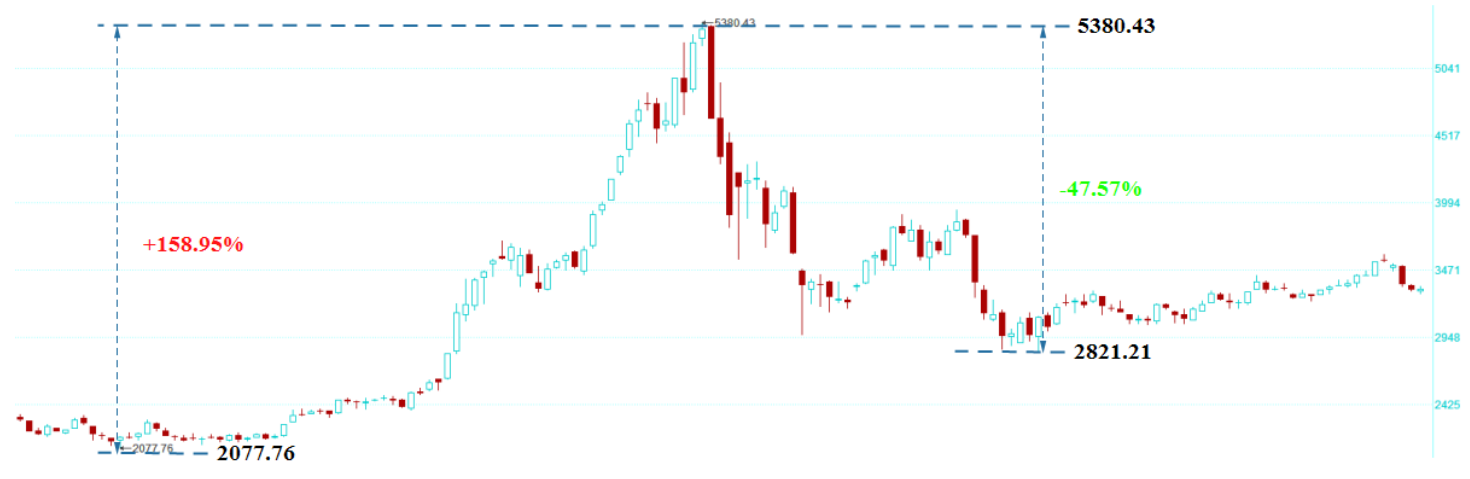

Figure 2 Weekly candlestick chart for CSI 300 index (2014-2016). 


\subsection{International market}
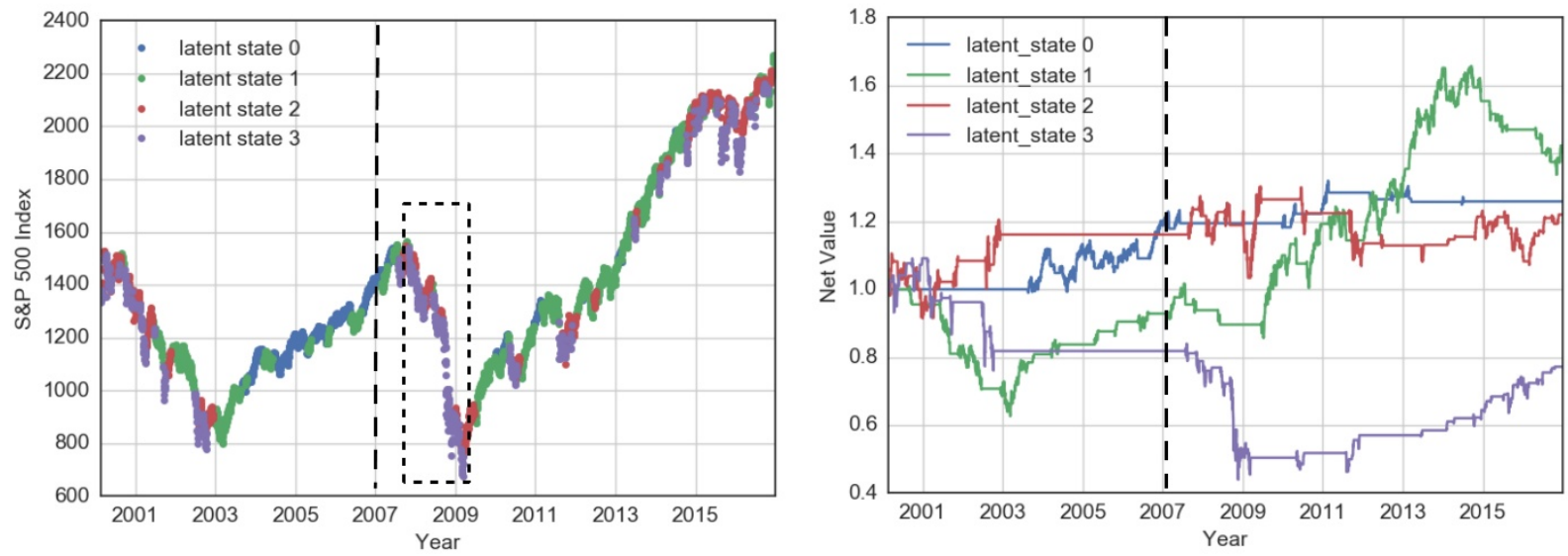

Figure 3 4-states HMM model for S\&P 500 index.

The model is also tested on S\&P 500 index in American market. The advantage of American market is that it has accumulated a large amount of historical data. We use data over 2000 to 2006 for training and data over 2007 to 2016 for testing. According to the experimental results, we get the highest potential cumulative return using 4-state model. The benchmark yield of this period is 140.27\%, and the results has been shown in Figure 3 and Table 5. It can be seen that states 0, 1 represent the rising trend in long cycle, and state 2 represents the market rebound, which can bring profits as well. The state 2 experiences loss period at the beginning, becomes a selected state until 2009 and contributes great profits to the whole strategy. State 3 represents the sharp falling trend, which bring huge losses. It can be implied that the trained HMM model avoid the sharp falling trend during the financial crisis in 2008. Benefit from more mature market environment, less states is required to obtain huge and stable return.

Table 5 Part of results on S\&P 500 index (2007-2016).

\begin{tabular}{|c|c|c|c|c|c|c|c|c|c|c|}
\hline \multirow{2}{*}{$\begin{array}{c}\text { States } \\
\text { number }\end{array}$} & \multirow{2}{*}{$\begin{array}{c}\text { Selected } \\
\text { number }\end{array}$} & \multirow{2}{*}{$\begin{array}{l}\text { Winning } \\
\text { rate }\end{array}$} & \multicolumn{2}{|c|}{ Frequency } & \multirow{2}{*}{ Return } & \multirow{2}{*}{$\begin{array}{l}\text { Annualized } \\
\text { yield }\end{array}$} & \multirow{2}{*}{$\begin{array}{l}\text { Maximum } \\
\text { drawdown }\end{array}$} & \multirow{2}{*}{$\begin{array}{l}\text { Sharpe } \\
\text { ratio }\end{array}$} & \multirow{2}{*}{ Cost } & \multirow{2}{*}{$\frac{\text { return }}{\text { drawdown }}$} \\
\hline & & & Open & Close & & & & & & \\
\hline \multirow{2}{*}{4} & 2 & $58.00 \%$ & 50 & 50 & $103.42 \%$ & $10.27 \%$ & $12.23 \%$ & 1.81 & 22847 & 8.46 \\
\hline & 3 & $54.29 \%$ & 36 & 35 & $236.63 \%$ & $23.49 \%$ & $12.23 \%$ & 1.41 & 24043 & 19.35 \\
\hline
\end{tabular}

\subsection{Comparison}

\subsubsection{Other methods}

\section{a) Double-MA (Moving Average)}

The double-MA strategy can be described by Equation (2).

$$
\begin{gathered}
\mathrm{MA}_{\mathrm{n}}=\frac{\sum_{\mathrm{i}=0}^{\mathrm{n}-1} \text { close }_{\mathrm{T}-\mathrm{i}}}{\mathrm{n}} \\
\left\{\begin{array}{l}
\text { buy, if } \mathrm{MA}_{\text {short }}>\mathrm{MA}_{\text {long }} \text { and position }=0 \\
\text { sell, if } \mathrm{MA}_{\text {short }}<\mathrm{MA}_{\text {long }} \text { and position=1 }
\end{array}\right.
\end{gathered}
$$


The biggest weakness of MA-based strategy derives from the delay of MA, bringing about longrun losses during volatile stock markets. Only during the huge bull or bear market could this strategy make huge profits or avoid huge losses. However, there will be a huge bull or bear market every 7-8 years generally, therefore, MA-based strategy has a longer cycle of return. Moreover, to find out the best parameters for MA strategy is very difficult, which gives rise to overfitting easily.

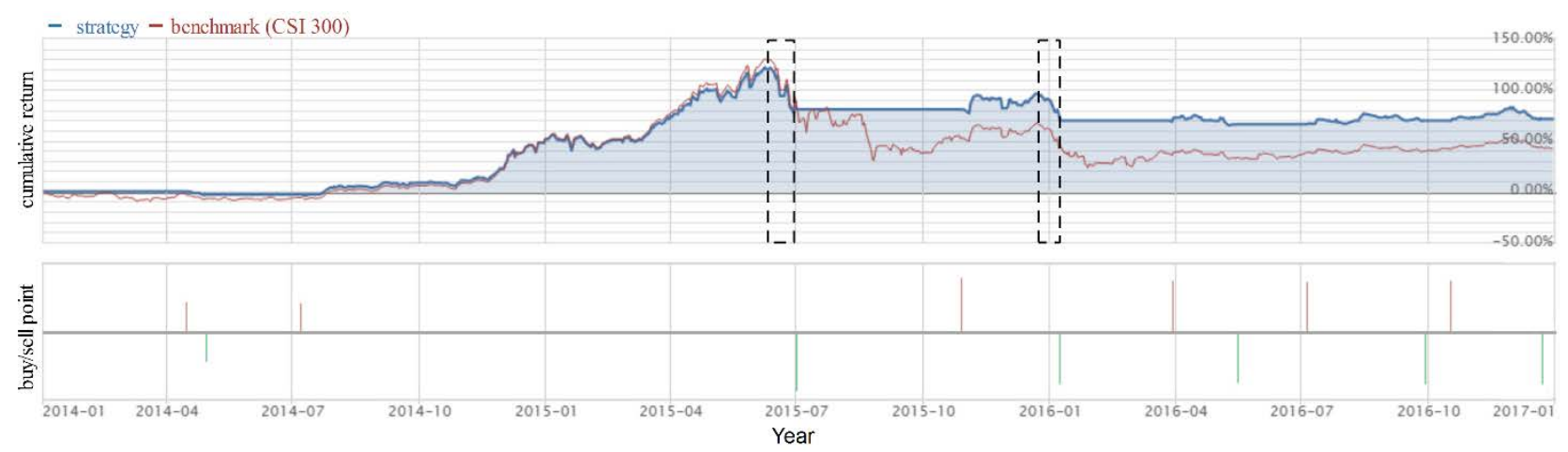

Figure 4 Return curve and buy/sell points for double-MA (10/60) strategy.

Ten combinations in total, containing short period MAs of 5, 10, 20, 30 and long period MAs of $10,20,30,60$, are tested. Figure 4 shows the result of double-MA strategy of MA10/MA60 from 2014 to 2016. 23.73\% annualized yield is obtained with 25.68\% drawdown and only 6 times of trading. As shown in black squares, there is always a time lag at the beginning of the fall, which leads to relatively large drawdown.

\section{b) K-means}

K-means is tested with the same features mentioned above. Without dynamic states selection, the 5-state k-means model brings $15.19 \%$ of the annualized return with $13.29 \%$ of the drawdown on CSI 300 from 2014 to 2016. Through the use of dynamic states selection, the 8-state K-means model could bring about $84 \%$ of the potential return and a low drawdown of $12.74 \%$. The winning rate is less than $50 \%$ for most cases and trading frequency is higher than that of the HMM model.

K-means applies daily features as description for each day. Similar days with similar features will be clustered into one state. Compared with HMM, k-means doesn't take relationship between adjacent days into consideration, which results in frequent states transitions and great trading costs. We can see from Figure 5 that this strategy doesn't make any profit during volatile market.

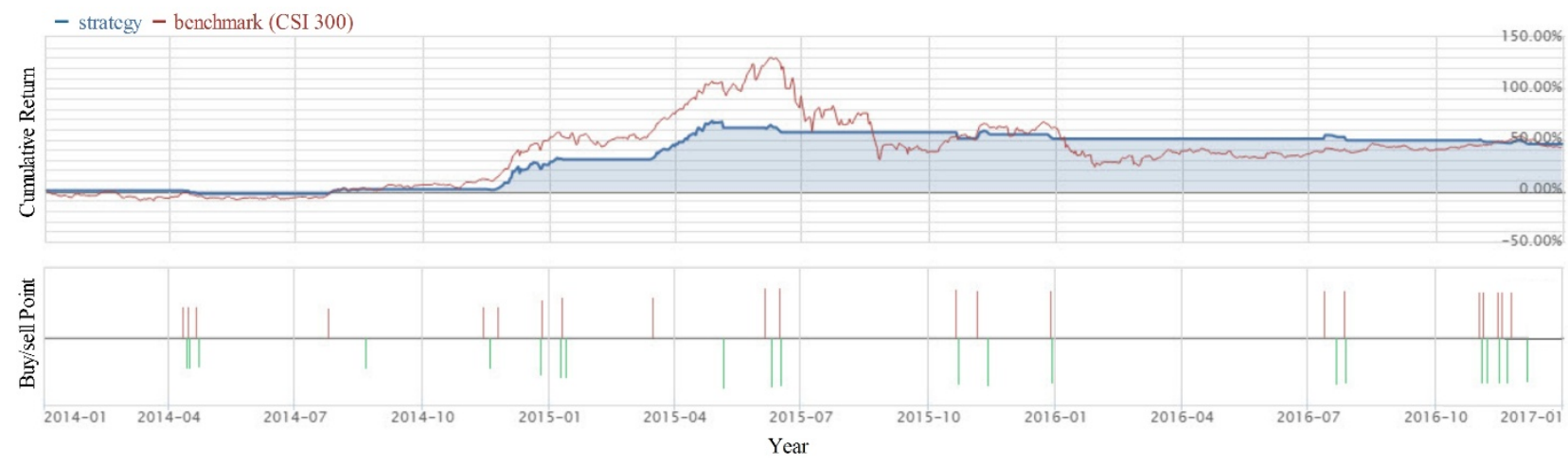

Figure 5 Result of K-means (5 clusters) strategy on CSI 300 index (2014-2016). 


\subsubsection{Advantages}

As mentioned in part 2.3.1, HMM brings advantages on clean parameters, robustness and good interpretability. It's also found better at detecting risk in time and keeping drawdown at a low level compared with other common strategies. The comparative results of 3 methods are shown in Table 6 , all the statistical results is calculated without dynamic states pool.

From the perspective of return expectation, HMM-based strategy has higher return rate compared with k-means, which is caused by more reasonable assumption of Markov property and has similar performance with MA method. However, MA-based strategy performs poorly on controlling drawdown due to the delay itself. HMM-based strategy brings about higher winning rate and also lower trading frequency compared with k-means. And it has less trading commission in average meaning.

Table 6 Statistical results of 3 methods.

\begin{tabular}{|c|c|c|c|c|c|c|c|c|c|c|}
\hline \multirow{2}{*}{ Strategy } & \multirow{2}{*}{ Statistics } & \multirow{2}{*}{$\begin{array}{l}\text { Winning } \\
\text { rate }\end{array}$} & \multicolumn{2}{|c|}{ Frequency } & \multirow{2}{*}{ Return } & \multirow{2}{*}{$\begin{array}{l}\text { Annualized } \\
\text { yield }\end{array}$} & \multirow{2}{*}{$\begin{array}{l}\text { Maximum } \\
\text { drawdown }\end{array}$} & \multirow{2}{*}{$\begin{array}{l}\text { Sharpe } \\
\text { ratio }\end{array}$} & \multirow{2}{*}{ Cost } & \multirow{2}{*}{$\frac{\text { return }}{\text { drawdown }}$} \\
\hline & & & Open & Close & & & & & & \\
\hline \multirow{4}{*}{ HMM } & Avg. & $56.82 \%$ & 13.3 & 12.8 & $44.88 \%$ & $14.35 \%$ & $14.95 \%$ & 1.37 & 4558 & 3.37 \\
\hline & Max & $100.00 \%$ & 26.0 & 26.0 & $83.69 \%$ & $26.76 \%$ & $24.37 \%$ & 1.44 & 8973 & 5.48 \\
\hline & Min & $34.62 \%$ & 2.0 & 1.0 & $3.24 \%$ & $1.04 \%$ & $6.98 \%$ & 1.26 & 483 & 0.32 \\
\hline & SD & $17.70 \%$ & 7.2 & 7.5 & $20.33 \%$ & $6.50 \%$ & $5.79 \%$ & 0.06 & 2462 & 1.71 \\
\hline \multirow{4}{*}{ K-means } & Avg. & $40.11 \%$ & 34.1 & 34.0 & $28.39 \%$ & $9.47 \%$ & $17.96 \%$ & 0.60 & 11062 & 1.82 \\
\hline & Max & $53.06 \%$ & 80.0 & 80.0 & $45.54 \%$ & $15.19 \%$ & $35.99 \%$ & 1.08 & 23056 & 3.43 \\
\hline & Min & $31.03 \%$ & 20.0 & 20.0 & $-1.32 \%$ & $-0.44 \%$ & $13.29 \%$ & -0.02 & 7065 & -0.04 \\
\hline & SD & $7.15 \%$ & 16.2 & 16.2 & $11.49 \%$ & $3.83 \%$ & $5.90 \%$ & 0.27 & 4451 & 0.90 \\
\hline \multirow{4}{*}{ MA } & Avg. & $47.53 \%$ & 15.6 & 15.5 & $45.33 \%$ & $15.13 \%$ & $31.52 \%$ & 0.49 & 5428 & 1.65 \\
\hline & Max & $61.54 \%$ & 44.0 & 44.0 & $71.12 \%$ & $23.73 \%$ & $46.60 \%$ & 0.78 & 13902 & 3.32 \\
\hline & Min & $33.33 \%$ & 6.0 & 5.0 & $10.85 \%$ & $3.62 \%$ & $20.26 \%$ & 0.13 & 1990 & 0.27 \\
\hline & SD & $8.37 \%$ & 11.2 & 11.3 & $18.94 \%$ & $6.32 \%$ & $8.07 \%$ & 0.20 & 3452 & 0.95 \\
\hline
\end{tabular}

\section{Conclusion}

In conclusion, HMM has the ability to identify the market states. It can be used to select suitable opportunities to trade and protect portfolios from stock plunge in either Chinese or American market. Besides, it has better performance on sensibility and stability compared with double-MA and k-means. In this paper, we provide a complete process on how to build a strategy based on HMM and prove the feasibility of proposed procedure.

For future work, more intelligent dynamic state selection mechanism is required to facilitate further study. The current method belongs to static condition and cannot monitor dynamic changes of states. It's quite probable to miss great profit space when the state can't meet specified conditions or suffer huge drawdown when the state meets the conditions. And we are also thinking about applying this model in combination with other strategies as a basic judgment to current market. For proposed procedure itself, more excellent controllability can be expected by adding position control and stop-loss or take-profit strategy.

\section{References}

[1] Guidolin, M. and A. Timmermann. (2007) Asset allocation under multivariate regime switching. Journal of Economic Dynamics \& Control, 31(11), 3503-3544.

[2] De Angelis, L. and L.J. Paas. (2013) A dynamic analysis of stock markets using a hidden Markov model. Journal of Applied Statistics, 40(8), 1682-1700. 
[3] Salhi, K., et al. (2016) Regime switching model for financial data: Empirical risk analysis. Physica aStatistical Mechanics and Its Applications, 461, 148-157.

[4] Cao, L. and F.E.H. Tay. (2001) Financial forecasting using support vector machines. Neural Computing \& Applications, 10(2), 184-192.

[5] Galeshchuk, S. (2016) Neural networks performance in exchange rate prediction. Neurocomputing, 172, 446452.

[6] Bebarta, D.K., T.E. Sudha, and R. Bisoyi. (2015) An Intelligent Stock Forecasting System Using a Unify Model of CEFLANN, HMM and GA for Stock Time Series Phenomena, in Emerging Ict for Bridging the Future, Vol 2, S.C. Satapathy, et al., Springer-Verlag Berlin: Berlin, 485-496.

[7] Hassan, R. and B. Nath. (2005) Stock market forecasting using Hidden Markov Model: A new approach, in 5th International Conference on Intelligent Systems Design and Applications, Proceedings, H. Kwasnicka and M. Paprzycki, Ieee Computer Soc: Los Alamitos, 192-196.

[8] Park, S.H., et al. (2009) Forecasting Change Directions for Financial Time Series Using Hidden Markov Model, in Rough Sets and Knowledge Technology, Proceedings, P. Wen, et al., Springer-Verlag Berlin: Berlin, 184-191.

[9] Seethalakshmi, R., B. Krishnakumari, and V. Saavithri. (2012) Gaussian Kernel based HMM for Time series Data Analysis, in Conference Proceedings of 2012 International Conference on Management Issues in Emerging Economies (Icmiee), 105-109.

[10] Khan, W., et al. (2016) A survey on the state-of-the-art machine learning models in the context of NLP. Kuwait Journal of Science, 43(4), 95-113.

[11] Paramonov, P. and N. Sutula. (2016) Simplified scoring methods for HMM-based speech recognition. Soft Computing, 20(9), 3455-3460.

[12] Fierrez, J., et al. (2007) HMM-based on-line signature verification: Feature extraction and signature modeling. Pattern Recognition Letters, 28(16), 2325-2334.

[13] Chen, F.S., C.M. Fu, and C.L. Huang. (2003) Hand gesture recognition using a real-time tracking method and hidden Markov models. Image and Vision Computing, 21(8), 745-758.

[14] Sed'a, P. and J.A.J. del Rio. (2016) Testing the Weak Form of Efficiency on Chinese Stock Market, in European Financial System 2016: Proceedings of the 13th International Scientific Conference, J. Krajicek, J. Nesleha, and K. Urbanovsky, Masarykova Univ: Brno, 669-677. 